\title{
Reasonable Basis for Media Judicial Supervision Under the Scope of Good Governance of Good Law
}

\author{
Sun Manman ${ }^{1,2}$, Shi Lei ${ }^{1}$, Wang Yilin $^{3}$ \\ ${ }^{1}$ College of Marxism, Xi'an University of Science and Technology, Xi'an, P. R. China \\ ${ }^{2}$ College of Humanities and Foreign Languages, Xi'an University of Science and Technology, Xi'an, P. R. China \\ ${ }^{3}$ College of Economics and Management, Shanghai University of Electric Power, Shanghai, P. R. China
}

Email address:

smm01@163.com (Sun Manman), 1610997257@qq.com (Shi Lei),wangyilin08@163.com (Wang Yilin)

${ }^{*}$ Corresponding author

\section{To cite this article:}

Sun Manman, Shi Lei, Wang Yilin. Reasonable Basis for Media Judicial Supervision Under the Scope of Good Governance of Good Law International Journal of Law and Society. Vol. 4, No. 3, 2021, pp. 159-164. doi: 10.11648/j.ijls.20210403.11

Received: May 27, 2021; Accepted: June 29, 2021; Published: July 10, 2021

\begin{abstract}
Good governance of good law are the substantive rule of law, not only need the law to be good law, but also need the legal governance effect to be good governance. The key to achieve good governance of good law is the strict adherence to law, also need to assist in fair and democratic governance. The philosophical methods of judicial trial under good governance of good law is "Legalism-led Consequentialism Supplement", When there is a legitimacy crisis arising from the second-order reasons (i.e legal rules), it is necessary to use consequentialism to consider the law and other first-order reasons to make judgment. The application of consequentialism brings the judgment of media supervision and professional justice to a limited extent consistency, and the judicial timely response to the needs of social concerns, to a certain extent, it increases the smoothness of judicial supervision, but the two are naturally in conflict. The reasonable judicial supervision of media should be based on the requirement of tool rationality and value rationality in order to ensure the justice.
\end{abstract}

Keywords: Good Governance of Good Law, Judicial Philosophy Method, Media Judicial Supervision, Reasonable Basis

\section{Introduction}

Judicial Supervision of media has its legitimacy, which can not only promote justice, but also achieve justice in a visible way. Under the background of good governance of good law, we pay attention to the value of the rule of law to ensure that the dominant position of ruleism is undoubtedly established, and it also establishes the relative supplementary status of consequentialism, which makes the judgment standards of media supervision and professional justice have a certain degree of consistency in a limited range, and the justice responds to the needs of social concerns in a timely manner, to a certain extent, the smoothness of judicial supervision has been increased, and some scholars directly suggest that public opinion and public will be taken as the standard of distinguishing complex cases, so as the basis for the application of the consequential trial method [1]. However, there is a certain conflict between the characteristics of media supervision and professional justice, and the media supervision power is a power outside of the administrative, legislative, and judicial powers, and it has a tendency to abuse, in order to make the media supervision playing better role of fairness guarantee, and to prevent the influence of public opinion on judicial independence or the phenomenon of trial by public opinion, this thesis studies the reasonable basis of media judicial supervision behavior. This topic studies the reasonable basis of media's 'judicial supervision' behavior, which helps to form a timely and effective media supervision system, and can also serve the exploration of the theory of socialist legal supervision with Chinese characteristics from a micro perspective.

\section{China's Rule of Law Is Good Governance of Good Law}

The rule of law can be the governance by law \& rules, otherwise the governance by good law. The socialist rule of law with Chinese characteristics is different from the general 
rule of law. It is a kind of good governance of good law. Good governance of good law are different from merely rule by law, the latter may belong to rule by bad law since the law may include evil rules. Good governance of good law is also different from the rule of good law. Although both are the governance of good law, the former also requires that the governance itself has value, that is, the realization of the effect of the substantive rule of law not only depends on good law but also includes good governance.

As for the good law, adopted by the Fourth Plenary Session of the 18th CPC Central Committee of the "Decision of the Central Committee of the Communist Party of China on Several Major Issues concerning the Comprehensive Promotion of the Rule of Law" (referred to as the "Decision") considered that " it should be people-oriented, implementing the core socialist values, reflecting the will of the people, the principle of justice, fairness and openness should run through the whole legislative process" [2]; For good governance, the Decision emphasizes, "fully perform the government functions according to the law... put public participation, expert demonstration, collective discussion decision identified as a legal procedure for major administrative decisions, adhere to the strict, standardized, fair and civilized law enforcement." "Ensuring a just administration of justice... improve the system to ensure the independent and impartial exercise of the judicial and procuratorial power in accordance with the law... promoting the strict administration of justice, promoting the strict administration of justice... ensuring the people's participation in justice" [2]. At the first meeting of the CPC Central Committee for the Comprehensive Governing of Law, Xi Jinping made it clear that we should promote core socialist values through all links of legislation, law enforcement, justice and law - abiding, and make the socialist rule of law a good governance of good law [3]. It can be seen that the socialist rule of law with Chinese characteristics is good law of good governance. In order to better understand the rule of law in China, the specific interpretation of good governance of good law is as follows:

First, "good governance of good law " refers to the "law" which means legal statutes. It is a kind of positive law, reflecting the will of the state, and has a certain legal form created by the state. Law has a broader scope, is a series of natural rules, and belongs to the prior universal principle that produces positive rules." In fact, all the various rules that guide humans to live together, provide a basis for human behavior to comply with, and thereby provide stable behavior expectations, can be called law. [4] "The scope of positive law is relatively narrow. In the Western civil law system it refers to statutory law, common law system refers to statutory law and case law, and in my country it refers to statutory law, judicial interpretation, and customary law (private law)."The rule of law should have two meanings: the established law is universally obeyed, and the law that everyone obeys should itself be a well-made law. [5] "It can be seen that Aristotle believed that 'the rule of law' is the enacted law. Some scholars hold the opposite view and believe that the law consisted in 'the rule of law' should be understood broadly."
The rule of law refers to a legitimate multi - party rule of law, Party members to obey the Party Constitution is legitimate, and villagers to township regulations and common law are also legitimate. This means that the true meaning of "rule of law" is based on the position of "legal pluralism", which emphasizes the pluralistic governance of customary law, state law, party law, moral ethics, natural law and so on." [6] The author believes that the process of cognition is correct, but the conclusion is inappropriate. It is precisely because it emphasizes the common governance of laws, norms and ideas such as national law, customary law, party regulations, ethics, natural law, etc., that the rule of law does not include but does not exclude the combined governance of other normative elements. Therefore, national governance can be said to be pluralistic co-governance. But the rule of law is legal governance.

Secondly, the "law" of good governance of good law is a "good law" that conforms to certain substantive requirements and formal requirements. "Similar to the city - state polity, the law is good or bad, just or unjust .......Laws must be made according political. [5] "The essential elements refer to the elements of value possessed by law. The value has the social attribute, the different social value view is different, the different social good law standard is different, but the value also has the certain similarity. In addition to the inherent rational values of the law such as fairness, justice and public will, which are the unified standards of good laws, the rule of law in China should also have its own rational value, such as civil rights, people's interests, harmony, happiness, substantive justice and so on, to reflect the value form of the core socialist values and traditional Chinese virtues. The formal requirement refers to the requirement that law becomes law, regardless of good governance of good law. Fuller believes that the law should have the internal moral nature of the law, namely Fuller eight, including universality, publication, caution of retroactivity, clear expression, avoid contradictions, avoid the impossible things [7]."'The inherent morality of law... is concerned not with the substantive objectives of the rules of law, but with the ways in which a system of rules governing human behaviour is constructed and managed in such a way that such a system is not only effective, but also retains the qualities required of a rule [7]."

Finally, the "governance" of the rule of law should be "good governance". At present, the "good governance" in the practice and theory of China is the corresponding transliteration of "western good governance", which does not have the same understanding as the traditional meaning of good governance in China. "The meaning of good governance" is the remaining meaning after removing the nondemocratic and non-legal governance factors of good governance [8]. Basic elements of good governance include the rule of law, democracy, justice, transparency, responsibility, effectiveness, order, and integrity [9]. Good governance is the goal of social governance, reflected in the rule of law, requires legal governance behavior itself must have certain value, specific include: good law enforcement refers to the enforcement itself being lawfully, democratic and 
fair; Good justice refers to strict justice, fair justice, and public participation. "Good governance reflects the value pursuit of substantive rule of law, emphasizing... respect for the authority of the Constitution and the law, act in strict accordance with the law, and at the same time not mechanically enforce the law, and be good at applying the law in a creative way according to the principles of law and the spirit of the rule of law, thereby compensating for the law Limitations. [10] "

\section{The Philosophy of Judicial Trial of Good Governance of Good Law}

Justice under good governance of good law emphasizes the value of fairness, and justice is the highest value of justice. Justice in accordance with the law and in accordance with good law, although it is the key to realizing fairness, it is inevitable to be powerless under some circumstances. The China Plan for the Construction of the Rule of Law (2020 2025) pointed out that we should firmly grasp the deep seated problems affecting judicial justice and restricting judicial ability, adhere to the combination of meeting the national conditions and following the judicial laws, and build a fair, efficient and authoritative socialist judicial system with Chinese characteristics [11]. Professor Zhang Wenxian believes that taking the path of socialist justice with Chinese characteristics and building a fair, efficient and authoritative socialist judicial system is the fundamental law for the healthy development of the people's judicial cause and the smooth progress of court work [12].

\subsection{The Judicial Philosophy Method of "Legal Rule Leading Consequence Supplement"}

When it comes to the rule of law, the first thing that comes to mind is justice, and when it comes to justice, the most important is the judicial idea or judicial philosophy method. An unfair trial has even more than ten crimes. Because crime is ignoring the law - like polluting the water, and unfair trials destroying the law - like polluting the source of water. "I think Bacon's words are profound [13]. Therefore, fairness is the lifeline and soul of justice. How to ensure that the fundamental requirements of justice are realized?

According to the regularity of realizing fairness, strict judicature is the demand of instrumental rationality for realizing judicial justice. Law is the carrier of Justice, according to the Law to achieve justice, which is the original intention of the rule of law. According to the law of Judicature, judicature is the act of running the law, the Act of judgment and adjudication, and further the act of reaching the judgment and adjudication through the operation of the law. The essence as well as the core content of Judicature is to make judgment lawfully. Therefore, the judicature can realize the judicial justice only if it is based on the legal ruling strictly. However, due to its artificial nature, the law will always be accompanied by natural defects, making the strict administration of Justice and the fair administration of justice outside the unity of sometimes conflicted beyond their uniformity. Therefore, when the law arises legitimacy crisis or when the law is absent the realization of justice requires the judge to find another way.

With the rule of law orientation of good governance of good law in recent years, with the orientation of good governance of good law into the rule of law, the legal philosophy method of judicial trial in our country has appeared the consequentialist trial method in addition to the principle of legal doctrine. Based on the belief in the existing legal norms, legalism is committed to the realization of judicial justice from a certain article, a certain category, a certain department, even the whole legal system, that is, to achieve judicial fairness from the inside of the legal norms; It is committed to seek the appropriate legal and social science reasons from the consequences, and consider the realization of judicial justice through a comprehensive approach. Consequentialism skillfully makes up for the inherent defects of the law, such as the unfairness and the absence of law when the law is limited, but highlights the risks of not strictly following the law and endangering the rule of law, at the same time, because of its own need for overall consideration, lack of unity, specificity, laying a complementary position of consequentialism, so that the rule of the dominant position in the judiciary is indisputable [14].

\subsection{How to Define the Applicable Critical Point of "Legal Dominant Consequence Supplement"}

Some scholars have suggested that legalism should be applied to general cases, and social science legal methodology should be applied to difficult and complex cases, the author also suggests that the difficult and complex cases should be divided by public opinion and public will... all the cases with public attention and reflecting great public opinion should be regarded as the difficult cases and the consequentialist method should be applied [1]. In general cases, applying legalism, and in difficult and complex cases applying legalism plus consequentialism, but the method of dividing difficult cases is not appropriate. It is true that in practice, there are many cases of correcting the case in the second instance or the retrial procedure, and the cause does come from public opinion attention, but the author believes that such a definition will cause the following problems: First, public opinion can often pay attention to the conflict between legal and social consequences based on the verdict of the first instance. Such a definition will make logical mistakes, because difficult cases were originally defined to prevent the occurrence of conflict results, but now there is a logic of "the result is defined as". Second, the lack of rationality to define objective problems by subjective standards. According to this logic, public opinion is not concerned is not a difficult case. If public opinion is lazy, some objective difficult cases deny their nature because they are not concerned? Third, such a definition will induce some interested parties in cases to manipulate public opinion to leverage the judiciary, improperly abandon dogmatism and apply consequential methods, thus affecting the process of the rule of law. It can be seen that public opinion attention is often 
only an external cause of a judicial error correction mechanism, and cannot be regarded as a normal independent impartial judicial mechanism.

To define the critical point of "Supplement of norm-dominated consequence", we can use LARZ's action theory to set up a reasonable answer. The reasons for action can be divided into the first-order reasons and the second-order reasons. The second-order reasons are exclusive, and the first-order reasons can not be applied when there are the second-order reasons, when there is no second-order reason or the second-order reason can not be the second-order reason, the first-order reason is needed to take into account for judge. Because of its nature, the legal rules is solidified as the second-order reason of the highest strength under the simple situation, and the first-order reason such as legal philosophy and legal ethics is absolutely prohibited when the rule of law exists. However, the second-order reason is solidified by the authoritative subject. When the legitimacy crisis of the legal authority appears, the situation in which the explanation is solidified as the reason of the highest intensity behavior has changed from simple to complex, and the case belongs to the complicated and difficult category, the law in existence at this time is no longer a second-order reason, but must apply to all first-order reasons for overall judgment.

How to identify the crisis of legal legalization? Three normative propositions of Larz view of service authority can give answers, including absolute assertively question, dependency proposition and legitimate proposition of standard [15]. "In the later article Authority: A View of Service Authority, Lz added the conditions of independence: in the case that NJT is met, the actor followed the authority instruction to follow the reasons than self - decision. That is, obedience to authority is only necessary when compliance with the reason is more correct than self - determination." [16] concept of service authority applies to all practical authority, and the law applies this standard, that is, firstly, solidified by the authority body as an exclusive reason, again itself belongs to the first cause of action, secondly, the action has the best effect, and finally, the strongest correctness according to this reason. When the cured second - order reason, no longer belong to the strongest cause of action, more dependence is not a cause of action, there is the legal authority became the second order reason legitimate crisis, began to become the first order or is not a cause of action, then need to apply all the first order reasons, including the legal rules, or exclude the other first - order reasons to consider the judgment conclusion.

\section{Reasonable Basis for Media Judicial Supervision Under Good Governance of Good Law}

The Decision pointed out that ensuring fair judicature and improving judicial credibility ...Strengthen the oversight of the judicial activities ...Judicial organs should respond timely to social concerns. Standardize media reports on cases to prevent public opinion from affecting judicial fairness.
Supervision of judicature by media is a double - edged sword that has a dual role in judicature. Although judicature under good governance of good law becomes a necessary supplement, it requires judicature to respond to social concerns in a timely manner, which increases the smoothness of judicial supervision to a certain extent. However, there is naturally a big conflict between the media judgment standards and professional judicature, and the freedom of media supervision and the independence requirements of professional judicature are conflicting with each other. It is necessary to explore the reasonable basis of the media's judicial supervision behavior.

First, the tool rationality requirements. (1) Free supervision. The original intention and purpose of supervision is to ensure justice, which should be guaranteed by free supervision. Supervision is the process in which the supervision subject questions, supervises and denies the object under supervision. To perform these duties, the supervision subject must give it the freedom of supervision. Marx argued that "without freedom of press and publication, all other freedom will become a bubble. [17] "Of course, free supervision is not the same as unbounded supervision. (2) Real supervision. Truth should include three meanings, objective, accurate and comprehensive. Since media supervision can be in the form of reports or comments, objective, for media reports, it means that facts are objectively existing, the form is not subjective, and the attitude is objectively neutral; for reviews, it means that objective materials should be used as the object of comment., Give subjective knowledge in an objective and rational manner; Accurate means that reports and comments strictly conform to reality and are not biased. Comprehensive refers to all directions, all perspectives, without concealment or omission. (3) Supervision afterwards. Independence is the natural requirement of justice. Independence requires courts and judges to maintain a proper distance from the outside society, free from interference from other powers and public opinion, and complete justice within the system purely. Otherwise, supervision will be based on the object instead of supervision, it is influence and intervention. Some people may question that public opinion belongs to public opinion, and courts and judges are not affected by public opinion. In fact, non-interference between justice and public opinion requires a good and mature legal environment. The socialist legal system needs to be improved and established. Under circumstances, the outcome of the trial will inevitably fluctuate in accordance with public opinion. (4) active supervision. Media supervision is also a kind of power. Power can not be given up, and it has to be acted upon. Morbid supervision, such as surface supervision, omission supervision and weak supervision, directly affects the realization of the purpose of supervision, and makes judicial power lose one party's strong restriction, affect the realization of judicial fairness. In practice, for some reason, the media is often controlled by the government, and for some reason, the judiciary is often associated with the government. Therefore, on the one hand, the phenomenon of the media supervision being suppressed by force or guidance occurs from time to time, on the other hand, the media itself 
deliberately avoid or dragonfly water phenomenon will be everywhere.

Second, the value rationality requirements. (1) Fair supervision. Media supervision is also a kind of power, and there is also an abuse problem. Just supervision is the primary requirement of supervision ethics on the exercise of media supervision power. Justice is equity and just. Equity refers to treating people and things on the same principles, and just refers to doing what they should do to put everyone in his own place. Since fairness and justice are divided between form and substance, the former builds on equality, giving the same rights and obligations to different individuals, regardless of the final result justice or not; the latter builds on inequality, giving the most disadvantaged different opportunities and interests and focusing on the summary justice of the final result. The essence of socialist society is common prosperity. To achieve common prosperity, first, we must give equal fairness and justice to all people, and then give the best benefit of the least beneficiaries on the basis of unbalanced and inadequate outcome development. It can be seen that the justice of socialist countries pays attention to both form and substantive justice, and form justice is the main path of substantive justice. Judicial supervision of the media not only lies in the fair treatment of rights and obligations in supervision cases in a form, but also lies in the evaluation of the distribution of opportunities and interests in supervision cases with substantive justice. (2) Supervision in good faith. Good faith supervision refers to supervision with pure purpose and minimum harm supervision, and the supervision behavior is not harmful to the supervised object and related personnel as much as possible. When the harm is inevitable, the damage is minimized, and the goal should not exceed the value pursued. value. For courts and judges, supervision is to correct deviant behaviors and bring them back to justice, not to harm, except for reasonable damages paid by the supervised person as a result of the supervision behavior; for the relevant parties or other persons involved in the supervision, especially the victims Interests should not be harmed innocently due to the supervision behavior. For example, in the supervision process involving the suicide and death of the party's information materials, special consideration should be given to the feelings of family members; in the case of sensitive personal information, even if the person concerned agrees, and the media itself would not risk a commission of law, you must also be kind and empathetic for his (other) people.

\section{Conclusion}

The rule of law in China is a good rule of law and it belongs to the substantive rule of law, which is different from the "rule of good law" which is also the substantive rule of law, and is even more different from the "rule by law" of the formal rule of law. In the context of good governance of good law, the fundamental adherence to the judicial trial philosophy is still to follow the law, however, due to the natural limitations of the law, it will inevitably be difficult to achieve the value of fair in justice by relying solely on lawful judicature, in the emergence of a crisis of just conduct which becomes a second-order cause for action, that is, when the situation changes from simple to complex, when the law that is solidified as the highest-strength second-order reason in a simple situation is abdicated as a first-order reason or even no longer a reason for action, need to use consequentialism to comprehensively consider all the first-order reasons to arrive at the judgment result. The purpose of media to supervise judicature is to ensure justice. Due to the natural conflict between the freedom of media supervision and the independence of professional judiciary, there are obvious differences in the determination of facts and the judgment of results between the two. Although the conflicts and differences between the two under good governance of good law can be relieved to a certain extent in a limited range, it is still inevitable to affect judicial independence or even the emergence of public opinion trials. The article uses the principle of rationality as a method to derive the requirements of an effective media supervision system in a good governance of good law environment, which is beneficial to promote the realization of the purpose of media supervision and judicial protection of just, and can also indirectly serve the exploration of the supervision theory of the rule of law with Chinese characteristics.

\section{Acknowledgements}

We thank the academic editors and anonymous reviewers for their kind suggestions and valuable comments. This research was supported by the Philosophy and Social Science Prosperity Project of Xi'an University of Science and Technology (No. 2017SZ02).

\section{References}

[1] Chen Hui. On the Value and Orientation of Consequentialism in the Legal Adjudication [J]. The Jurist, 2018, (04): 35-50, 192.

[2] Decision of the Central Committee of the CPC on Some Major Issues Concerning Comprehensively Promoting the Rule of Law [J] China Legal Science, 2014 (06): 5-19.

[3] Xi Jinping presided over the first meeting of the CPC Central Committee for the Comprehensive Governing of Law and stressed the strengthening of the Party's centralized and unified leadership over the Comprehensive Rule of Law to better guarantee the role of maintaining fundamental stability, stable expectations and long - term benefits [J]. The People's Congress, 2018 (09): 4-5.

[4] Qiang Shigong. Party Constitution and Constitution: Construction of the Republic of Rule of Law [J]. Beijing Cultural Review, 2015 (04): 20-31.

[5] Aristoteles. Politicss [M]. Wu Shoupeng, translate. Beijing: The Commercial Press, 1994: 200, 149.

[6] Qiang Shigong. The Path and Pattern of China's Rule of Law: Global Vision and Chinese Experience [J]. Administration Reform, 2019 (08): 21-28. 
[7] Furrer. The Morality of Law [M]. Zheng Ge, translate. Beijing: The Commercial Press, 2006.

[8] Zhou Anping. The Relations between Good Governance and the Rule of Law - Clarify the misunderstanding of the current understanding [J]. Studies in Law and Business, 2015 (04): $75-82$

[9] Yu Keping. Democratic Governance and political Reform in China [M]. Beijing: Central Compilation \& Translation Press, 2012.

[10] Dai Jianhua. The rule of law should be a combination of good law and good governance [N]. Study Times, 2019-09-18 (003).

[11] Issued by the Central Committee of the Communist Party of China. China Construction Plan for Rule of Law (2020-2025) [J]. China Anti-Counterfeiting Report, 2021 (01): 68-77.

[12] Zhang Wenxian. Basic Theory and Practical Process of Judicial Reform of People's Court [J]. Law and Social Development, 2009, 15 (03): 3-14.
[13] Xi Jinping. Explanation on the Decision of the CPC Central Committee on Some Major Issues Concerning Comprehensively Promoting the Rule of Law [J]. Qiu Shi, 2014 (21): 16-23.

[14] Sun Haibo. The Contest of "Consequence Consideration" and "Legalism"__ Between the nightmare and the dream of legal method [J]. Law and Social Development, 2015, 21 (02): 167-177.

[15] Joseph Raz. The Morality of Freedom Oxford university press, 1986.

[16] Ye Huichen. Practical grounds and authority Justification on the authority theory of Rz [J] Jin Ling Law Review, 2015 (02): 105-118.

[17] Marx and Engels: The Complete Works of Marx and Engels (Volume 1) [M]. Compilation and Translation of Marx and Engels Lenin Stalin of the Central Committee of the Communist Party of China, Beijing: People's Publishing House, 1995: 201. 